\title{
Longitudinal changes in the nature, severity and frequency of COPD exacerbations
}

\author{
G.C. Donaldson, T.A.R. Seemungal, I.S. Patel, S.J. Lloyd-Owen, T.M.A. Wilkinson, J.A. Wedzicha
}

Longitudinal changes in the nature, severity and frequency of COPD exacerbations. G.C. Donaldson, T.A.R. Seemungal, I.S. Patel, S.J. Lloyd-Owen, T.M.A. Wilkinson, J.A. Wedzicha. (C) ERS Journals Ltd 2003.

ABSTRACT: Exacerbations are an important feature and outcome measure in chronic obstructive pulmonary disease (COPD), but little is known about changes in their severity, recovery, symptom composition or frequency over time.

In this study 132 patients (91 male; median age $68.4 \mathrm{yrs}$ and median forced expiratory volume in one second (FEV1) $38.4 \%$ predicted) recorded daily symptoms and morning peak expiratory flow.

Patients were monitored for a median of 918 days and 1,111 exacerbations were identified. Patients with severe COPD (Global Initiative for Chronic Obstructive Lung Disease (GOLD) category III, $n=38$ ) had an annual exacerbation frequency of $3.43 \cdot \mathrm{yr}^{-1}, 0.75 \cdot \mathrm{yr}^{-1}$ higher than those with moderate COPD (GOLD II, $\mathrm{n}=94$ ). Exacerbation frequency did not change significantly during the study. At exacerbation onset, symptom count increased to 2.23, relative to a baseline of 0.36 set 8-14 days previously, and this increase rose by $0.05 \cdot \mathrm{yr}^{-1}$. Recovery to baseline levels in symptoms and FEV1 took longer $\left(0.32\right.$ and 0.55 days $\left.\cdot \mathrm{yr}^{-1}\right)$. Sputum purulence at exacerbation became more prevalent over time by $4.1 \% \cdot \mathrm{yr}^{-1}$ from an initial value of $17 \%$.

The results of this study suggest that over time, individual patients have more symptoms during exacerbations, with an increased chance of sputum purulence and longer recovery times.

Eur Respir J 2003; 22: 931-936.
Academic Unit of Respiratory Medicine, St. Bartholomew's and Royal London School of Medicine and Dentistry, London, UK.

Correspondence: J.A. Wedzicha

Academic Unit of Respiratory Medicine Dominion House

St. Bartholomew's Hospital

London EC1A 7BE

UK

Fax: 442076018616

E-mail: j.a.wedzicha@gmul.ac.uk

Keywords: Chronic obstructive pulmonary disease

cohort studies

exacerbations

Received: April 72003

Accepted after revision: September 32003

This study was supported by the British Lung Foundation and GlaxoSmithKline.
Patients with chronic obstructive pulmonary disease (COPD) are prone to exacerbations that are an important determinant of health-related quality of life, morbidity and mortality $[1,2]$. Exacerbations are characterised by acute worsening of symptoms, increased airway inflammation and physiological deterioration [3]. They have become an important outcome measure in the study of therapy in COPD. Recently, two studies have suggested that exacerbations may affect disease progression by accelerating the forced expiratory volume in one second (FEV1), a decline characteristic of COPD [4, 5]. The authors have estimated that exacerbations may account for $\sim 25 \%$ of the FEV1 decline in COPD [5]. However, to date there is no information about the history of exacerbations in COPD patients.

The authors have also previously shown that a significant number of exacerbations do not recover to baseline levels in symptoms and/or lung function [6] and it is possible that this nonrecovery may be the mechanism by which exacerbations contribute to lung function decline. Alternatively, the impact of exacerbations may increase over time, resulting in greater airway inflammation, which contributes to the accelerated FEV1 decline. Previously, the authors have shown that exacerbation length (recovery) is related to the magnitude of the acute deterioration (severity) in lung function and symptoms at exacerbation, with exacerbation impact defined by the combination of the severity and the length of recovery [6]. However, there is no previous data available as to how exacerbation impact changes over time.

This study followed 132 COPD patients over 6 yrs and collected data on 1,111 exacerbations. Patients recorded on diary cards daily peak expiratory flow (PEF) and/or spirometry and increase in symptoms. The authors used a set of indices, based on previous descriptions of the time course of symptoms and lung function associated with an exacerbation [6], which divided an exacerbation into a prodromal or baseline period, onset and recovery. The objective of the current study was to investigate whether the frequency, symptom composition and indices of severity and recovery of exacerbations changed over time.

\section{Methods}

\section{Patients}

A total of 177 patients with COPD were recruited from the outpatients dept of the London Chest Hospital in the first 5 yrs of this 6-yr study. In the first year, 99 patients were recruited consecutively and from then on those who subsequent withdrew or died were replaced. The recruitment criteria were an FEV1 $<70 \%$ predicted from sex, age and height, a FEV1/forced vital capacity (FVC) ratio $<70 \%$, $\beta_{2}$ agonist reversibility $<15 \%$ and/or $<200 \mathrm{~mL}$, the absence of asthma, bronchiectasis, bronchial carcinoma or other significant respiratory disease, and a willingness to participate in a long-term study. Of these 177 patients, 132 were selected for this analysis on the basis that they had recorded diary card data on a minimum of 365 days. The reasons for 45 patients failing to record sufficient data were withdrawal, death or 
inadequate completion of diary cards, combined with late enrollment. The 132 patients did not differ significantly from the 45 excluded patients in any of the characteristics reported in table 1 , except for a slightly lower PEF (152 versus $181 \mathrm{~L} \cdot \mathrm{min}^{-1}$; Wilcoxon $\mathrm{p}=0.0179)$ and $\mathrm{FVC}(2.14$ versus $2.44 \mathrm{~L} ; \mathrm{p}=0.039)$. This cohort has been the subject of previous publications, which investigated the relationship of COPD exacerbations to quality of life [1], inflammatory markers [3], lung function decline [5], time course of symptoms and lung function [6], respiratory viruses [7], fibrinogen [8] and bacterial colonisation [9]. This is the first longitudinal analysis on the history of exacerbations with 6 yrs of data.

\section{Enrollment}

At recruitment, measurements were made of FEV1, FVC and PEF by rolling seal spirometer (Sensor Medic Corp., Yorba Lindo, CA, USA), reversibility to $400 \mu \mathrm{g}$ inhaled salbutamol and arterialised ear lobe blood gases (model 278 Blood Gas Analyzer; Ciba-Corning, Medfield, MA, USA) [10]. A history was taken of smoking habits (years of smoking, current smoking status). Patients were asked about their symptoms of dyspnoea, sputum production, wheeze and cough. The patients were also asked about their long-term inhaled and oral steroid use. The study had ethics approval from the Ethics Committee of the East London and City Health Authority and patients provided written informed consent.

\section{Monitoring and exacerbation}

The patients were asked to record postmedication PEF (Mini-Wright Clement Clark International Ltd, Harlow, UK) and any increase over their normal, stable condition in symptoms of dyspnoea, sputum purulence or sputum volume (major symptoms) and colds (nasal discharge/congestion), wheeze, sore throat, cough (minor symptoms) on diary cards each morning. A total of 35 randomly selected patients also

Table 1.-Characteristics of the 132 chronic obstructive pulmonary disease patients in the study, and the 35 who recorded forced expiratory volume in one second (FEV 1 ), measured at recruitment

\begin{tabular}{lcc}
\hline Patients $n$ & 132 & 35 \\
Age yrs & $68.4(62.5-73.7)$ & $65.1(60.7-73.6)$ \\
FEV1 L & $0.99(0.74-1.3)$ & $1.08(0.77-1.4)$ \\
FEV1 \% predicted & $38.4(27.0-49.9)$ & $36.0(25.4-50.0)$ \\
FEV1 \% reversibility & $5.4(0-12.6)$ & $6.1(0-12.8)$ \\
FVC L & $2.45(1.82-2.93)$ & $2.6(1.99-2.90)$ \\
FEV $1 / \mathrm{FVC} \%$ & $42.3(33.2-53.1)$ & $45.3(33.1-53.7)$ \\
$\mathrm{PEF} \mathrm{L} \cdot \mathrm{min}^{-1}$ & $181(139-250)$ & $240(162-300)$ \\
$\mathrm{Pa}, \mathrm{O}_{2} \mathrm{mmHg}^{-1} \mathrm{Hg}$ & $68.4(62-73)$ & $68.4(62-75)$ \\
$\mathrm{Pa}, \mathrm{CO}_{2} \mathrm{mmHg}$ & $44.2(41-48)$ & $44.7(42-50)$ \\
$\mathrm{Smoking}$ yrs & $42(31-50)$ & $40(27-46)$ \\
$\mathrm{Sex}$ males & 68.9 & 88.6 \\
Chronic dyspnoea & 48.5 & 54.3 \\
Chronic wheeze & 32.6 & 34.3 \\
Chronic cough & 47.0 & 42.9 \\
Chronic sputum production & 53.8 & 45.7 \\
History of smoking & 95.4 & 94.3 \\
Smoking at recruitment & 31.1 & 34.2 \\
Inhaled steroids & 90.2 & 85.7 \\
Oral steroids & 9.0 & 14.2 \\
\hline
\end{tabular}

Data are presented as median (interquartile range) or $\%$ of patients. FVC: forced vital capacity; PEF: peak expiratory flow; $\mathrm{Pa}_{\mathrm{a}} \mathrm{O}_{2}$ : arterial oxygen tension; $\mathrm{Pa}, \mathrm{CO}_{2}$ : arterial carbon dioxide tension. measured daily FEV1 and FVC using a hand-held spirometer (Micro Medical Ltd, Chatham, Kent, UK). Exacerbation onset was taken as the first of two or more consecutive days with increase in either two or more major symptoms, or any one major symptom plus any minor symptoms $[1,3,5,6]$. Symptoms were disregarded in identifying onset if recorded continuous in the 5-day period preceding a suspected exacerbation onset. Two subjects separately identified exacerbations (at clinic visits and at data entry) and then later resolved disagreements in diagnosis and timing. Exacerbations for which no or insufficient diary-card symptoms were recorded by the patient, were on occasion identified by hospital admission for an acute exacerbation of COPD or by questioning at clinic visits. Patients with increased symptoms were encouraged to contact the clinical team by telephone, and were seen prior to treatment generally within $48 \mathrm{~h}$. The exacerbations seen by the clinical team were classified as "reported exacerbations" with those unseen termed "unreported exacerbations". Records were kept of hospitalisation throughout, and from November 1996 onwards, records were available of the date of initiation and type of treatment prescribed to patients both at the authors' clinic and also that prescribed by the patient's general practitioner (GP).

\section{Statistical analysis}

Data are presented as mean (SD) or median (interquartile range (IQR)) and comparisons performed by unpaired t-test, Wilcoxon matched-paired sign-rank test or a Chi-squared test, as appropriate. Differences in exacerbation frequency between groups were estimated using generalised linear models assuming a poisson distribution in the frequency, and thus $95 \%$ confidence intervals $(95 \% \mathrm{CI})$ are reported rather than IQR.

\section{Indices of exacerbation severity}

Exacerbation severity with respect to lung function and symptom count (the sum of the binary coded presence or absence of seven respiratory symptoms) was assessed over a 51-day period. Baseline was taken as the mean of a parameter over days 14-8 preceding exacerbation onset, as no significant changes in lung function and symptoms were seen over this time period. The change in any parameter associated with exacerbation was taken as the difference between baseline and the day of onset. Recovery was the time from onset for a 3day moving average to equal or exceed the baseline. A moving average was used to avoid false early recoveries when lung function improved for just a single day, but then remained below baseline for a few more days. The authors analysed recovery from exacerbation at 35 days because in most clinical studies a patient not having an exacerbation for 4-6 weeks would be considered stable. Exacerbation nonrecovery was taken as recovery taking $>35$ days [6].

To assess changes over time of these indices, cross-sectional, generalised linear models were fitted using the xtgee command in Stata 5.0 (Stata Corporation, Texas, USA). These models examine time variations independently of cross-section variations in panel data [11]. The distribution of the dependent variable was specified after inspecting histograms of the data and the independent variable was time in years.

\section{Exacerbation frequency and symptom composition}

Each patient was considered to have started on the same day (day $1=$ November 1, 1995), whether enrolled on or after 
that date, to avoid bias from patients recruited later during the study who may have had very high or low exacerbations frequencies. The subsequent 6 yrs were then divided into 24 quarter-yr periods. Within each period, the number of exacerbations was divided by the number of patients involved, and multiplyed by four, to give an annual exacerbation frequency. The symptom percentage was calculated by dividing the number of exacerbations with a given symptom by the total number of exacerbations and multiplying by 100 . Linear regression was then used to assess time trends in frequency and symptoms. Quarter year periods were chosen as a compromise between year long periods, in which the number of patients at the start and end of the year would differ markedly, and between month long periods in which too few exacerbations would occur to sensibly calculate the symptom percentages. The analysis was repeated with allowance for seasonality, as the findings could potentially be biased by enrollment during the winter or withdrawal just before winter when exacerbations are more common. The exacerbation frequency was calculated as above, but without aligning the start dates of each patient. Sine and cosine terms with a year period, in addition to the trend term, were then fitted by the regression technique described above.

The authors chose not to analyse changes over time in the interval between exacerbations using cross-sectional models, since interval data will over estimate exacerbation frequency towards the end of the study period, when completed intervals for patients with infrequent exacerbations are less likely to be available relative to patients with frequent exacerbations. With the approach adopted by the authors, it was not sensible to analyse differences between groups, such as smoking status or drug therapy, as too few patients would be available in the later stages of the study, nor was the study designed with these analyses in mind.

\section{Results}

\section{Patients}

The 132 patients (91 male, 31 female) studied had moderateto-severe COPD (table 1). Of these, 119 patients took inhaled steroids daily $\left(1.53\right.$ (SD 1.1) $\mathrm{mg} \cdot \mathrm{day}^{-1}$ beclomethasone equivalents) and 12 patients took a mean 5.91 (3.0) $\mathrm{mg} \cdot \mathrm{day}^{-1}$ of oral prednisolone; 10 patients used both oral and inhaled steroids. The subgroup of 35 (31 male, four female) patients who recorded daily FEV1 and FVC were similar to the others for the characteristics reported in table 1, except they had a higher $\operatorname{PEF}(\mathrm{p}=0.001)$ and a higher percentage of males $(\mathrm{p}=0.003)$.

\section{Exacerbation frequency, changes over time}

The patients participated in the study for a median of 918 (IQR: 666-1.365) days. During the 6 yrs of the study, seven of the 132 patients had no exacerbations and eight patients had just one. There were a total of 1,111 exacerbations of which $971(87 \%)$ were identified from the symptom data recorded by the patients on their diary cards, $123(11 \%)$ by questioning about symptoms at clinic, six by hospital admission alone, eight by treatment by the authors or GP alone, and three were recorded as an exacerbation but other data lost. In total, $511(46.0 \%)$ of all exacerbations were reported and seen by the clinical team. The odds ratio of an exacerbation being reported to the authors clinic team, was $0.84(95 \% \mathrm{CI}$ : $0.78-0.91 ; \mathrm{p}<0.001)$ relative to the preceding year. However, the odds ratio of an exacerbation being treated by the authors or the patient's GP, relative to the prior year, did not change over time (0.93; 95\% CI: $0.84-1.03$; $\mathrm{p}=0.149)$.

The median exacerbation rate was 2.52 (IQR: 1.34-3.93) exacerbations $\cdot \mathrm{yr}^{-1}$. The exacerbation frequency was $3.43 \cdot \mathrm{yr}^{-1}$ (95\% CI: $2.7-4.2), 0.75 \cdot \mathrm{yr}^{-1}(0.08-1.43)$ higher $(\mathrm{p}=0.029)$ in patients $(\mathrm{n}=38)$ with severe COPD $(\mathrm{FEV} 1<30 \%$ pred and FEV1/FVC $<70 \%$ pred; Global Initiative for Chronic Obstructive Lung Disease (GOLD) category III), compared with those $(n=94)$ with moderate COPD (FEV1 $\geqslant 30 \%$ pred and $<80 \%$ pred and FEV1/FVC $<70 \%$ pred; GOLD category II) whose frequency was $2.68(2.35-3.01)$. The FEV1 in the two groups were $0.67 \mathrm{~L}$ (SD 0.14 ) and $1.22 \mathrm{~L}(0.4)$, respectively $(\mathrm{p}<0.001)$. There was no significant difference in exacerbation frequency between GOLD IIA and GOLD IIB.

There was no significant difference in the exacerbation frequency of those 35 patients who recorded FEV1, and FVC (3.17. $\mathrm{yr}^{-1}$; 95\% CI: 2.4-3.9) and the other 97 patients $\left(2.80 \cdot \mathrm{yr}^{-1} ; 2.5-3.1 ; \mathrm{p}=0.286\right)$. There was no significant difference in exacerbation frequency between the 64 patients who withdrew early from the study (median $3.06 \cdot \mathrm{yr}^{-1} ; 2.4-3.8$ ) and those who were still participating at the end of the study in November $2001\left(2.7 \cdot \mathrm{yr}^{-1} ; 2.3-3.1 ; \mathrm{p}=0.307\right)$. There was also no difference in exacerbation frequency between the 19 patients who died and the other 113 patients $\left(2.77\right.$ versus $2.92 \cdot \mathrm{yr}^{-1}$; $\mathrm{p}=0.724)$.

Annual exacerbation frequency for all 132 patients remained constant during the study, changing by only $-0.025 \cdot \mathrm{yr}^{-1}(95 \%$ CI: $-0.065-0.015 ; \mathrm{p}=0.208$ ) from a starting value of $2.88 \cdot \mathrm{yr}^{-1}$. The exacerbation frequency was also constant if allowance was made for seasonality $\left(-0.025 \cdot \mathrm{yr}^{-1} ;-0.054-0.003 ; \mathrm{p}=0.080\right)$, although there were significant winter peak to summer trough changes of 1.28 exacerbations $\mathrm{yr}^{-1}(\mathrm{p}<0.001)$. Over time, symptoms at exacerbation of both sputum purulence and volume rose by $4.12 \% \cdot \mathrm{yr}^{-1}(\mathrm{p}=0.004)$ and $5.25 \% \cdot \mathrm{yr}^{-1}(\mathrm{p}=0.001)$ respectively, whilst wheeze fell by $2.8 \% \cdot \mathrm{yr}^{-1}(\mathrm{p}=0.004)$ (fig. 1). There was no significant change in the other symptoms (table 2).

\section{Exacerbation severity, changes over time}

Table 3 shows estimates of the annual change in the timecourse indices and their value at the start of the study in November 1995. At the study start, symptom count at baseline was estimated as 0.36 and rose to 2.23 at exacerbation onset. Over time, symptom count did not rise significantly during the baseline period or at exacerbation onset, but their difference did increase by $0.05 \cdot \mathrm{yr}^{-1}(\mathrm{p}=0.047)$. FEV1 at baseline declined significantly by $-34.5 \mathrm{~mL} \cdot \mathrm{yr}^{-1}(\mathrm{p}<0.001)$ but there was no change over time in FEV1 at exacerbation onset. FVC did not change significantly over time at baseline or

Table 2. - Changes over time in the frequency of symptoms reported at exacerbation

\begin{tabular}{lcccc}
\hline Symptom & $\begin{array}{c}\text { Starting } \\
\text { value } \%\end{array}$ & $\begin{array}{c}\text { Annual } \\
\text { change } \% \cdot \mathrm{yr}^{-1}\end{array}$ & $95 \% \mathrm{CI}$ & p-value \\
\hline Dyspnoea & 60 & 1.30 & $-1.7-4.3$ & 0.383 \\
Sputum purulence & 17 & 4.12 & $1.4-6.8$ & 0.004 \\
Sputum volume & 34 & 5.25 & $2.2-8.2$ & 0.001 \\
Cold $^{\#}$ & 31 & -1.77 & $-3.7-0.02$ & 0.073 \\
Wheeze & 38 & -2.87 & $-4.7--1.0$ & 0.004 \\
Sore throat & 13 & -0.38 & $-1.7-0.9$ & 0.556 \\
Cough & 30 & -0.81 & $-2.3-0.7$ & 0.281 \\
\hline
\end{tabular}

The starting value estimates the percentage of exacerbations with a particular symptom had they all occurred at the start of the study and the annual change gives how this percentage changed over time. CI: confidence interval. \#: nasal congestion/discharge. 
Table 3. - Changes in indices of exacerbation baseline, recovery and nonrecovery over time

\begin{tabular}{|c|c|c|c|c|c|c|}
\hline & Starting value & Annual change & $95 \% \mathrm{CI}$ & p-value & Exacerbations $\mathrm{n}$ & Subjects $n$ \\
\hline \multicolumn{7}{|l|}{ Baseline } \\
\hline Symptom count ${ }^{\#}$ & 0.36 & -0.012 & $-0.04-0.01$ & 0.352 & 1045 & 123 \\
\hline PEF $\mathrm{L} \cdot \mathrm{min}^{-1}$ & 234 & -2.8 & $-4.3--1.3$ & 0.000 & 1043 & 123 \\
\hline FEV1 mL & 1034 & -34.5 & $-52--16$ & 0.000 & 221 & 32 \\
\hline FVC mL & 1856 & 18.0 & $-53-90$ & 0.623 & 199 & 31 \\
\hline \multicolumn{7}{|l|}{ At exacerbation onset } \\
\hline Symptom count & 2.23 & 0.034 & $-0.013-0.08$ & 0.153 & 1045 & 123 \\
\hline $\mathrm{PEF} L \cdot \mathrm{min}^{-1}$ & 217 & -0.81 & $-2.1-0.57$ & 0.249 & 1011 & 123 \\
\hline FEV1 mL & 966 & -17.8 & $-36-0.2$ & 0.052 & 212 & 32 \\
\hline FVC mL & 1743 & 39.6 & $-7.4-8.6$ & 0.099 & 190 & 31 \\
\hline \multicolumn{7}{|l|}{ Recovery time } \\
\hline Symptom count day & 8.4 & 0.32 & $0.20-0.44$ & 0.000 & 945 & 122 \\
\hline PEF day & 7.8 & -0.07 & $-0.18-0.03$ & 0.163 & 922 & 122 \\
\hline FEV1 day & 6.1 & 0.55 & $0.26-0.85$ & 0.000 & 199 & 31 \\
\hline \multicolumn{7}{|l|}{ Nonrecovery $>35$ days } \\
\hline Symptom count & & 1.00 & $0.88-1.14$ & 0.994 & 1045 & 123 \\
\hline PEF & & $0.95^{\bullet}$ & $0.85-1.07$ & 0.412 & 1043 & 123 \\
\hline FEV1 & & $1.12^{\top}$ & $0.81-1.53$ & 0.493 & 221 & 32 \\
\hline FVC & & $1.42^{\oplus}$ & $0.84-2.39$ & 0.185 & 199 & 31 \\
\hline
\end{tabular}

A normal distribution was assumed for data at baseline and at exacerbation onset. A poisson distribution was assumed for data on recovery, and a binomial distribution for nonrecovery. CI: confidence interval; PEF: peak expiratory flow; FEV1: forced expiratory volume in one second; FVC: forced vital capacity. "\#. symptom count the sum of the seven respiratory symptoms recorded each day, with presence/increased scored 1 and absence $0 ; \uparrow^{\uparrow}$ : the change from 1 yr to next in nonrecovery, data presented as odds ratio.

onset. At baseline PEF fell by $2.7 \mathrm{~L} \cdot \mathrm{min}^{-1} \cdot \mathrm{yr}^{-1}(\mathrm{p}<0.001)$ but PEF did not change at exacerbation onset over time $(p=0.249)$.

Recovery in FEV1, FVC and symptom count from exacerbation took significantly longer each year, by $0.55,0.85$ and 0.32 days $\cdot \mathrm{yr}^{-1}$, respectively (all $\mathrm{p}<0.001$ ). No change was seen in recovery of PEF. Similar results were found for exacerbations that were untreated, with recovery respectively taking $0.34,1.39$ and 0.39 days $\cdot \mathrm{yr}^{-1}$ longer (all $\mathrm{p}<0.013$ ). Again, changes in PEF recovery were nonsignificant.

Complete recovery to baseline levels did not always take place: 121 of $1,043(11.6 \%)$ never recovered in PEF, 100 of $1,045(9.6 \%)$ in symptom count, 22 of $221(10.0 \%)$ in FEV1 and 15 of $199(7.5 \%)$ in FVC. Table 3 also shows that there was no significant change in the number of exacerbations not recovering within 35 days over time.

\section{Drug treatment and hospitalisation, changes over time}

During the whole study, there were 65 hospitalisations for acute exacerbation of COPD, representing $5.9 \%$ of the 1,111 exacerbations. The odds ratio of hospitalisation increased by 1.26 each yr (95\% CI: $1.084-1.459 ; \mathrm{p}=0.002)$. The median length of stay in hospital was 11 days (IQR: 7-15 days) and did not change over time. Data collected over the last 5 yrs of the study showed that of 918 exacerbations, $223(24.3 \%)$ were treated with oral steroids and $525(57.1 \%)$ with antibiotics. There was a significant increase in treatment of exacerbations with oral steroids, as the odds ratio for treatment was 1.12 (95\% CI: $1.00-1.25 ; \mathrm{p}=0.051)$ relative to the previous year, but a fall in treatment with antibiotics, as the odd ratio was 0.91 (0.82-1.00; $\mathrm{p}=0.052)$.

\section{Discussion}

This is the first study to examine the history of exacerbations in patients with moderate-to-severe COPD. Patients were monitored with daily diary cards, recording daily symptoms, peak flow and/or spirometry. No previous study has prospectively collected such an extensive and detailed data set on exacerbations in a COPD patient group. The main findings were that over time exacerbation recovery took longer and symptoms at exacerbation of sputum purulence became more frequent.

In this study, exacerbations were identified according to criteria previously described and used consistently in all the authors' studies [1, 3, 5, 6]. Patients were encouraged to report exacerbations to the study team and about half of the exacerbations were reported and seen by the authors' physicians. Most studies of COPD exacerbation have depended on data involving healthcare utilisation, and so have included only exacerbations reported to healthcare professionals. The authors have previously shown that there are similarities between reported and unreported exacerbations in symptom composition, physiological and symptom changes and recovery $[1,6]$. These similarities may be due to under-reporting of exacerbation as COPD patients become accustomed to frequent symptom changes or experience depression [12] that may lead them to accept their situation. In the current study the authors have included both reported and unreported exacerbations and thus have a complete set of exacerbation data. The median exacerbation frequency in this 6-yr study is higher than in other studies [4, 13] at 2.52 events $\cdot$ patient ${ }^{-1} \cdot \mathrm{yr}^{-1}$ and this reflects the contribution of these unreported exacerbations.

The authors found no overall increase in exacerbation frequency over the 6-yr study period. There is little information in the literature about long-term trends in exacerbation frequency. KANNER et al. [4] reported an increase in the number of lower respiratory tract infections over time in continuous smokers but no change was found in sustained quitters. In this study, 41 patients $(31 \%)$ were current smokers and so an intermediate finding of no increase would be expected. Exacerbation frequency is widely thought to increase over time because exacerbations are more frequent in severe COPD. GREENBERG et al. [15] have reported that respiratory illnesses are more frequent $\left(3 \cdot \mathrm{yr}^{-1}\right)$ in moderate COPD than in mild COPD $\left(1.8 \cdot \mathrm{yr}^{-1}\right)$. In the current study, the authors found more exacerbations per year in patients with 
severe COPD (GOLD category III) than in moderate COPD (GOLD category II), 3.4 $\mathrm{yr}^{-1}$ compared with $2.7 \cdot \mathrm{yr}^{-1}$, respectively. The finding that there is little discernable change in frequency over 6 yrs seems reasonable in view of the following calculation. The difference in exacerbation frequency between moderate and severe COPD was $0.75 \cdot \mathrm{yr}^{-1}$, with a mean FEV1 in the two groups of 1.22 and $0.67 \mathrm{~L}$, respectively, so with a decline in FEV1 of $34.5 \mathrm{~mL} \cdot \mathrm{yr}^{-1}$ as in the current study, it would take 15.9 yrs for the frequency to rise by 0.7 , equivalent to an annual rise of only 0.047 exacerbations $\cdot \mathrm{yr}^{-1}$.

A large proportion of COPD exacerbations are triggered by respiratory viral infections [7], but there is no evidence to date of increased susceptibility to respiratory viral infection in patients with COPD compared with controls [15]. This would also help to explain the relative stability of the exacerbation frequency over time. Additionally, the relationship between disease severity and exacerbation frequency may not be linear over the different severities of COPD. This study is confined to patients with moderate-to-severe COPD. The stability of the exacerbation frequency may also be due to treatment with bronchodilators [16] and inhaled steroids [17, 18] as both have been shown to have an effect on reducing exacerbation frequency. The absence of any increase in exacerbation frequency over time could not be attributed to the early withdrawal or death of those patients with a high exacerbation frequency, as no difference was found between the median exacerbation rate of those who left the study early or who remained for the duration. In the current study, the authors found more hospitalisations over time. Others have also found that hospital admissions and readmissions are more common in patients with more severe COPD [15]. As exacerbation frequency did not increase much over time, this increase in hospital admissions possibly reflects the greater impact of an exacerbation on a patient whose health has become poorer as they have grown older, and whose increased risk of dying makes the physician more likely to admit.

An important finding in this study is that exacerbation recovery for FEV1, FVC and symptom count was significantly longer each year. These changes occurred despite an increasing use of oral corticosteroid therapy at exacerbation that has been shown to hasten lung function recovery $[19,20]$ but could have been contributed to by the decreased use of antibiotics. The authors have previously shown that symptom count and lung function changes at exacerbations are related to exacerbation recovery time [3]. The authors have also shown that exacerbations triggered by viral infections have higher symptom scores and are associated with an increased exacerbation length and recovery [7, 21]. Exacerbations triggered by respiratory viruses or symptomatic colds have been shown to have increased airway and systemic inflammatory markers at exacerbation onset, compared with those where no virus was detected or no cold was reported $[3,7,8$, 21]. Thus, more severe exacerbations are associated with increased airway and systemic inflammation and as patients with increased airway inflammation show faster FEV1 decline [22], this mechanism may explain how exacerbation severity affects disease progression.

The authors have recently shown that patients with lower airway bacterial colonisation (LABC) have a history of increased exacerbation frequency, compared with patients without LABC, and that these patients have more exacerbations associated with purulent sputum [9]. It has been shown that the presence and load of colonising bacteria in the lower airway may independently modulate airway inflammation in COPD [23]. In addition, LABC in COPD is associated with markers of disease severity [24-27]. One of the major findings in the present study was that, over time, exacerbations were associated with a greater prevalence of sputum purulence and volume. Sputum purulence is related to the detection of a
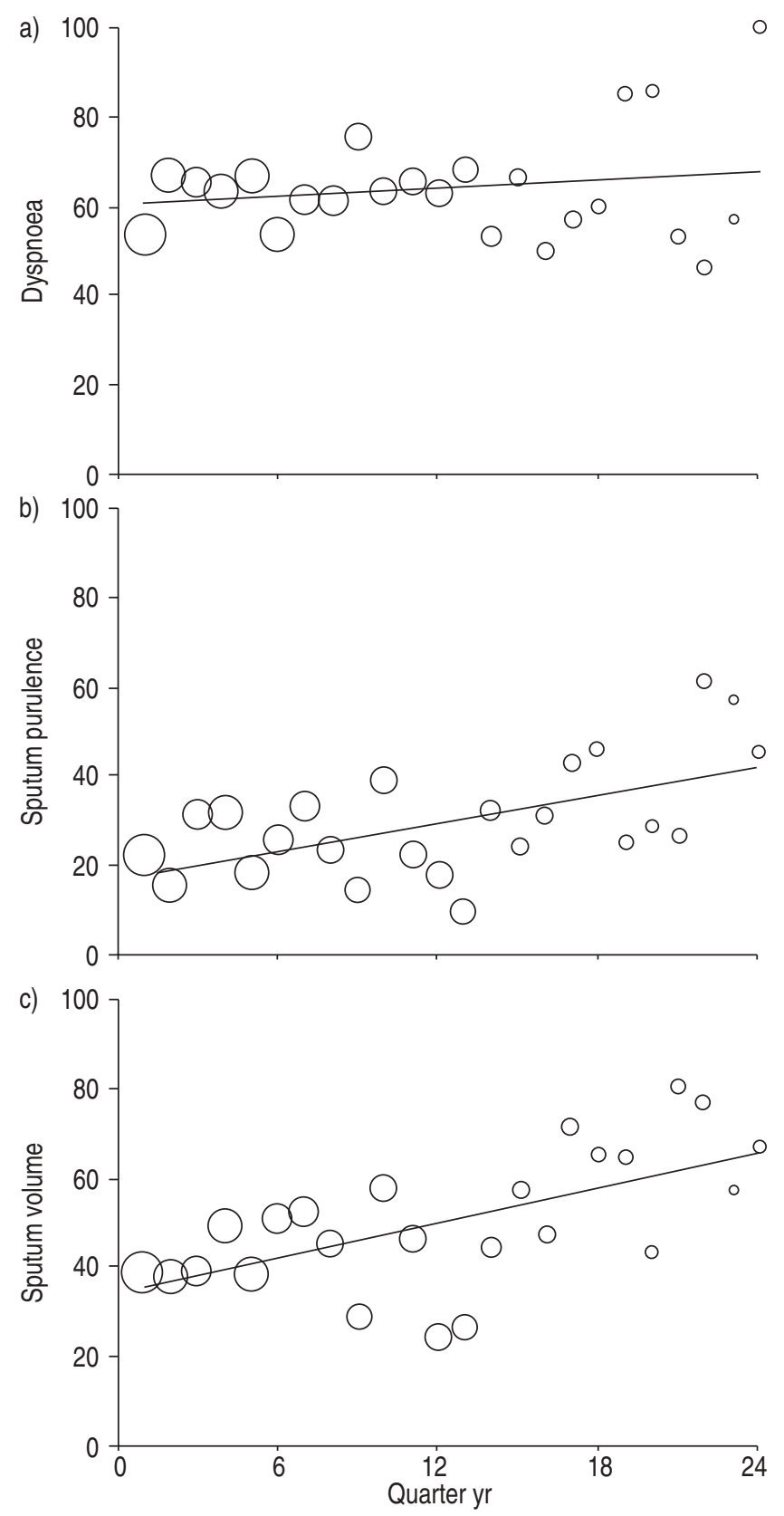

Fig. 1. - Percentage of exacerbations of a) dyspnoea, b) sputum purulence, and c) sputum volume, with the patient recording a major symptom on the day of onset, over time. Patients were assumed to have started the study on the same day. Circle size indicates the number of exacerbations recording in that quarter-year.

bacterial pathogen at exacerbation [28] and this data therefore suggest that over time, exacerbations may become more severe as they are associated with increasing bacterial loads and airway inflammation. This is also consistent with the finding that antibiotics were more effective at exacerbation in more severe patients [29].

The authors have also previously reported that COPD exacerbation may not recover to baseline [6] and in this study $\sim 10 \%$ of the exacerbation did not recover to baseline of either symptom count or peak flow. However, the authors did not find more nonrecovery over time and thus it seems that the decline in lung function is not specifically associated with incomplete recovery at exacerbation.

Exacerbations are an important determinant of health 
status and morbidity in chronic obstructive pulmonary disease. This study suggests that the increasing morbidity from exacerbation is due mainly to the increase in the duration of the exacerbation, rather than to an increase in frequency. Strategies aimed at reducing exacerbation duration, possibly by early treatment, need to be developed and may have important benefits to these chronic obstructive pulmonary disease patients.

Acknowledgements. The authors would like to thank M. Roland, A. Bhowmik and S. Leedham for assistance with data collection.

\section{References}

1. Seemungal TAR, Donaldson GC, Paul EA, Bestall JC, Jeffries DJ, Wedzicha JA. Effect of exacerbation on quality of life in patients with chronic obstructive pulmonary disease. Am J Respir Crit Care Med 1998; 157: 1418-1422.

2. Connors AF Jr, Dawson NV, Thomas C, et al. Outcomes following acute exacerbation of severe chronic obstructive lung disease. Am J Respir Crit Care Med 1996; 154: 959-967.

3. Bhowmik A, Seemungal TAR, Sapsford RJ, Wedzicha JA. Relation of sputum inflammatory markers to symptoms and lung function changes in COPD exacerbations. Thorax 2000; 55: $114-120$.

4. Kanner RE, Anthonisen NR, Connett JE. Lower Respiratory illnesses promote FEV1 decline in current smokers but not ex-smokers with mild chronic obstructive pulmonary disease. Am J Respir Crit Care Med 2001; 164: 358-364.

5. Donaldson GC, Seemungal TAR, Bhowmik A, Wedzicha JA. The relationship between exacerbation frequency and lung function decline in chronic obstructive pulmonary disease. Thorax 2002; 57: 847-852.

6. Seemungal TAR, Donaldson GC, Bhowmik A, Jeffries DJ, Wedzicha JA. Time course and recovery of exacerbations in patients with chronic obstructive pulmonary disease. Am J Respir Crit Care Med 2000; 161: 1608-1613.

7. Seemungal T, Harper-Owen R, Bhowmik A, et al. Respiratory viruses, symptoms, and inflammatory markers in acute exacerbations and stable chronic obstructive pulmonary disease. Am J Respir Crit Care Med 2001; 164: 1618-1623.

8. Wedzicha JA, Seemungal TA, MacCallum PK, et al. Acute exacerbations of chronic obstructive pulmonary disease are accompanied by elevations of plasma fibrinogen and serum IL-6 levels. Thromb Haemost 2000; 84: 210-215.

9. Patel IS, Seemungal TAR, Wilks M, Lloyd-Owen SJ, Donaldson GC, Wedzicha JA. Relationship between bacterial colonisation and the frequency, character, and severity of COPD exacerbations. Thorax 2002; 57: 759-764.

10. Pitkin AD, Roberts CM, Wedzicha JA. Arterialised earlobe blood gas analysis: an under used technique. Thorax 1994; 49: $364-366$

11. Liang K-Y, Zeger SL. Longitudinal data analysis using generalized linear models. Biometrika 1986; 73: 13-22.

12. Okubadejo AA, Jones PW, Wedzicha JA. Quality of life in patients with chronic obstructive pulmonary disease and severe hypoxaemia. Thorax 1996; 51: 4447.

13. Anthonisen NR, Manfreda J, Warren CP, Heshford EW,
Harding GKM, Nelson NA. Antibiotic therapy in exacerbation of chronic obstructive pulmonary disease. Ann Intern Med 1987; 106: 196-204.

14. Garcia-Aymerich J, Monso E, Marrades RM, et al. Risk factors for hospitalization for a chronic obstructive pulmonary disease exacerbation. EFRAM study. Am J Respir Crit Care Med 2001; 164: 1002-1007.

15. Greenberg SB, Allen MA, Wilson J, Atmar RL. Respiratory viral infections in adults with and without chronic obstructive pulmonary disease. Am J Respir Crit Care Med 2000; 162: $167-173$

16. Vincken W, van Noord JA, Greefhorst AP, et al. Improved health outcomes in patients with COPD during $1 \mathrm{yr}^{\prime} \mathrm{s}$ treatment with tiotropium. Eur Respir J 2002; 19: 209-216.

17. Burge PS, Calverley PM, Jones PW, Spencer S, Anderson JA, Maslen TK. Randomised, double blind, placebo controlled study of fluticasone propionate in patients with moderate to severe chronic obstructive pulmonary disease: the ISOLDE trial. BMJ 2000; 320: 1297-1303.

18. The Lung Health Study Research Group. Effect of inhaled triamcinolone on the decline in pulmonary function in chronic obstructive pulmonary disease. $N$ Engl J Med 2000; 343: 1902-1909.

19. Davies L, Angus RM, Calverley PM. Oral corticosteroids in patients admitted to hospital with exacerbations of chronic obstructive pulmonary disease: a prospective randomised controlled trial. Lancet 1999; 354: 456-460.

20. Niewoehner DE, Erbland ML, Deupree RH, et al. Effect of systemic glucocorticoids on exacerbations of chronic obstructive pulmonary disease. N Engl J Med 1999; 340: 1941-1947.

21. Seemungal TA, Harper-Owen R, Bhowmik A, Jeffries DJ, Wedzicha JA. Detection of rhinovirus in induced sputum at exacerbation of chronic obstructive pulmonary disease. Eur Respir J 2000; 16: 677-683.

22. Stanescu D, Sanna A, Veriter C, et al. Airways obstruction, chronic expectoration, and rapid decline of FEV1 in smokers are associated with increased levels of sputum neutrophils. Thorax 1996; 51: 267-271.

23. Sethi S, Murphy TF. Bacterial infection in chronic obstructive pulmonary disease in 2000: a state-of-the-art review. Clin Microbiol Rev 2001; 14: 336-363.

24. Soler N, Ewig S, Torres A, Filella X, Gonzalez J, Zaubet A. Airway inflammation and bronchial microbial patterns in patients with stable chronic obstructive pulmonary disease. Eur Respir J 1999; 14: 1015-1022.

25. Zalacain R, Sobradillo V, Amilibia J, et al. Predisposing factors to bacterial colonization in chronic obstructive pulmonary disease. Eur Resp $J$ 1999; 13: 343-348.

26. Monso E, Rosell A, Bonet G, et al. Risk factors for lower airway colonization in chronic bronchitis. Eur Resp J 1999; 13: $338-342$.

27. Hill AT, Campbell EJ, Hill SL, Bayley DL, Stockley RA. Association between airway bacterial load and markers of airway inflammation in patients with stable chronic bronchitis. Am J Med 2000; 109: 288-295.

28. Stockley RA, O'Brien C, Pye A, Hill SL. Relationship of sputum colour to nature and outpatient to management of acute exacerbations of COPD. Chest 2000; 117: 1638-1645.

29. Saint S, Bent S, Vittinghoff E, Grady D. Antibiotics in chronic obstructive pulmonary disease exacerbations: a meta-analysis. JAMA 1995; 273: 957-960. 